\title{
THE ACCURACY OF ENDORECTAL ULTRASONOGRAPHY IN RECTAL CANCER STAGING
}

\author{
ADRIAN COTE ${ }^{1,2}$, FLORIN GRAUR ${ }^{1,2}$, ANDREI LEBOVICI ${ }^{1,3}$, EMIL MOIS $^{1,2}$, \\ NADIM AL HAJJAR ${ }^{1,2}$, CODRUTA MARE ${ }^{4}$, RADU BADEA ${ }^{1,5}$, \\ CORNEL IANCU ${ }^{1,2}$
}

${ }^{1}$ Iuliu Hatieganu University of Medicine and Pharmacy, Cluj-Napoca, Romania ${ }^{2}$ Surgery Department, Prof. Dr. O. Fodor Regional Institute of Gastroenterology and Hepatology, Cluj-Napoca, Romania

${ }^{3}$ Radiology Department, Emergency County Hospital, Cluj-Napoca, Romania ${ }^{4}$ Department of Statistics-Forecasting-Mathematics, Faculty of Economics and Business Administration, Babes-Bolyai University, Cluj-Napoca, Romania ${ }^{5}$ Ultrasonography Department, Prof. Dr. O. Fodor Regional Institute of Gastroenterology and Hepatology, Cluj-Napoca, Romania

\section{Abstract}

Background and aims. The incidence of rectal cancer in the European Union is about 35\% of the total colorectal cancer incidence. Staging rectal cancer is important for planning treatment. It is essential for the management of rectal cancer to have adequate preoperative imaging, because accurate staging can influence the therapeutic strategy, type of resection, and candidacy for neoadjuvant therapy. The aim of this work is to evaluate the accuracy of endorectal ultrasound (ERUS) in rectal cancer staging.

Methods. A retrospective study was performed to assess the accuracy of ERUS by analyzing patients discharged from Regional Institute of Gastroenterology and Hepatology (IRGH) Cluj-Napoca, Romania, diagnosed with rectal cancer between 01 January 2011 and 31 December 2013. Patients who were preoperatively staged by other imaging methods and those who had ERUS performed in another service were excluded from the analysis. As inclusion criteria remained ERUS performed for patients with rectal cancer in IRGH Cluj-Napoca where they were also operated. We analyzed preoperative T stage obtained by ERUS and it was compared with the histopathology findings.

Results. The number of patients discharged with a diagnosis of rectal cancer were 200 (operated - 157) in 2011, 193 (operated - 151) in 2012, and 198 (operated - 142) in 2013. We analyzed a total of 51 cases diagnosed with rectal cancer who performed ERUS in IRGH Cluj-Napoca. The results according to the T stage obtained by ERUS and histopathology test were:

Under-stage $T 2=25.0 \%, T 3=7.9 \%$ of cases;

Over-stage $T 2=25.0 \%, T 3=31.6 \%$ and $T 4=60.0 \%$ of cases.

Less than $20 \%$ of patients underwent preoperative radio-chemotherapy.

Conclusions. ERUS is a method of staging rectal cancer which is human dependent. ERUS is less accurate for T staging of stenotic tumours, but the accuracy may still be within acceptable limits. Surgeons use ERUS to adopt a treatment protocol, knowing the risk of under-staging and over-staging of this method. The accuracy of ERUS is higher in diagnosing rectal cancer in stages T1, T2 and even in stage T3 with malignant tumor which is not occlusive. ERUS is less accurate for T staging of locally advanced and stenotic tumours. 
Keywords: rectal neoplasms, ultrasonography, neoplasm staging

\section{Background and aims}

Rectal cancer is one of the most common tumors of the digestive tract. It represents the second leading cause of death after lung cancer in men and the third leading cause of death in women after breast cancer and cervical cancer. Less than $3 \%$ of cases occur in patients under 40 years and the incidence increases rapidly over the age of 45 and doubles with each decade of life [1-4].

The incidence of rectal cancer in the European Union is about $35 \%$ of the total colorectal cancer incidence, i.e. $15-25 / 100000$ per year. The mortality is $4-10 / 100000$ per year with lower figures for females, higher for males [5].

The therapeutic attitude in front of a patient with rectal cancer is complex and depends on the tumor staging. The prognosis of patients with rectal cancer depends on tumor staging at the moment of diagnosis. Assessment of tumor invasion in the rectal wall and mesorectum fat and assessment of tumor invasion to the perirectal lymph node and distant metastasis determine the prognosis of a patient with rectal cancer [6].

The rectal cancer staging is made according to the TNM classification based on the American Joint Committee on Cancer.

Table I. Tumor nodes metastasis staging of rectal cancer based on the American Joint Committee on Cancer $7^{\text {th }}$ edition.

Primary tumor (T)

Tx Primary tumor cannot be assessed T0 No evidence of primary tumor

Tis Carcinoma in situ

T1 Tumor invades submucosa

T2 Tumor invades muscularis propria

T3 Tumor invades through the muscularis propria and into perirectal tissues

T4a Tumor penetrates to the surface of the visceral peritoneum

T4b Tumor directly invades or is adherent to other organs or structures

Regional lymph nodes (N)

Nx Regional lymph nodes cannot be assessed

N0 No regional lymph node metastasis

N1 Metastases in 1-3 regional lymph nodes

N1a Metastasis in 1 regional lymph node

N1b Metastases in 2-3 regional lymph nodes

Manuscript received: 14.04.2015

Received in revised form: 25.05.2015

Accepted: 12.06.2015

Address for correspondence: adrian.cote@gmail.com
N1c Tumor deposit(s) in the subserosa, mesentery, pericolic, or perirectal tissues without regional nodal metastasis

N2 Metastases in 4 or more regional lymph nodes

N2a Metastases in 4-6 regional lymph nodes

$\mathrm{N} 2 \mathrm{~b}$ Metastases in 7 or more regional lymph nodes

Distant metastasis (M)

M0 No distant metastasis

M1 Distant metastasis

M1a Metastasis confined to 1 organ or site (e.g., liver, lung, ovary, non-regional node, external iliac lymph node)

M1b Metastases in $>1$ organ/site or the peritoneum [6]

The option for one investigation or another for staging rectal cancer is based on availability and local expertise [6].

Endorectal ultrasound (ERUS) is one of the most widely used imaging methods for staging rectal cancer probably due to lower costs and patient accessibility to the equipment. ERUS was used to evaluate the pathology of the prostate and rectum since 1983 and in 1985 Hildebrandt and Feifel used it for staging rectal cancer. They defined for the first time the ultrasound TNM staging [7].

ERUS is performed with a high-frequency transducer covered with a special balloon which can be filled with water and the trans-anal probe is inserted into the rectum, or by introducing the transducer covered by a condom and filled with eco-gel. This approach can highlight the five layers of the rectal wall as alternating hyper-echoic and hypo-echoic bands $[6,8]$. The examination should be performed after previous cleaning of the colon or rectum at least by purgatives or enema solutions to avoid artifacts [9].

ERUS is an effective method in staging rectal cancer, but its accuracy depends on the experience of the examiner and the examination can be difficult in large rectal tumors or mobile ones. Therefore, the accuracy of ERUS in staging rectal cancer is controversial, especially in case of large and/or stenotic tumors [7].

Besides this method of staging rectal cancer, CT, MRI and PET may also be used. Endorectal ultrasound allows highlighting $\mathrm{T}$ and $\mathrm{N}$ stage of rectal cancer. According to other studies, the accuracy of ERUS is between 69\%-97\% for stages $\mathrm{T} 1$ and $\mathrm{T} 2$ and for stages $\mathrm{T} 3$ and $\mathrm{T} 4$ between 62\%-92\% with a fairly wide variability: $40 \%-100 \%$ for $\mathrm{T} 1$, T2 and 25\%-100\% for the T3, T4. Nodal staging accuracy is between $39 \%-83 \%$ by ERUS [10-13]. 
The sensitivity and specificity vary according to the tumor stage.

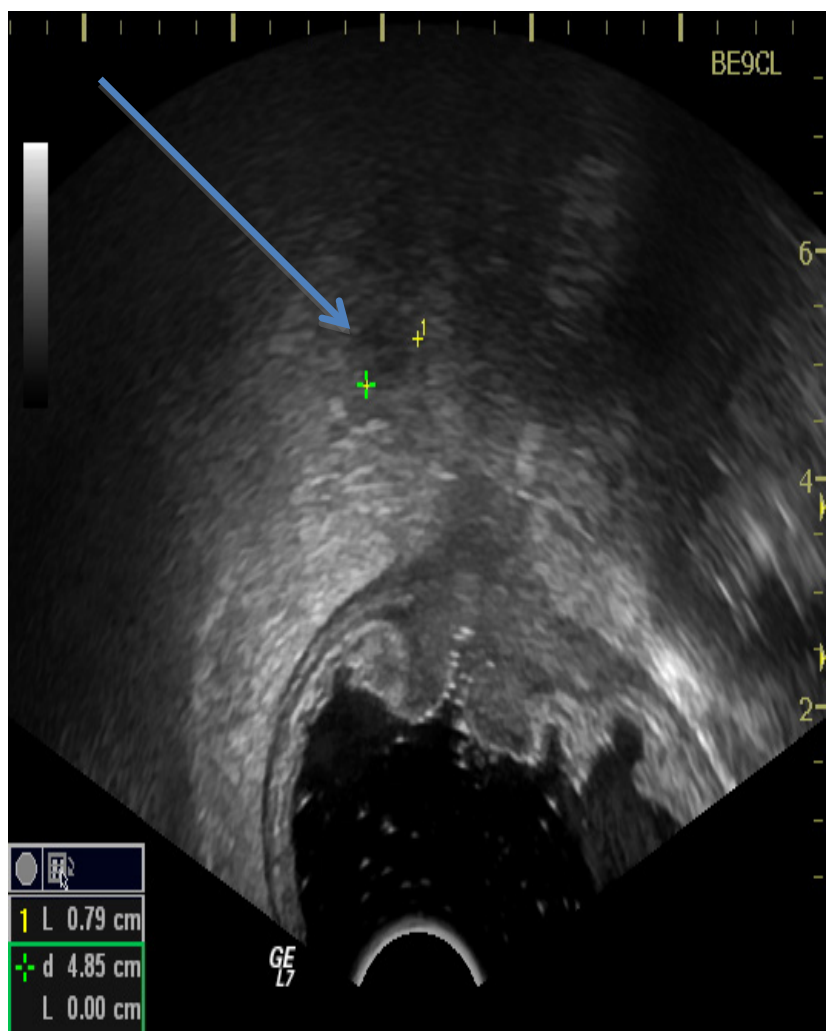

Figure 1. Metastatic lymph node revealed by ERUS.

In this report, we review the current roles and future perspectives of ERUS in the management of rectal malignancies, outlining its advantages and its limitations as well.

\section{Patients and methods}

A retrospective study was performed to assess rectal cancer staging by ERUS by analyzing patients discharged from Regional Institute of Gastroenterology and Hepatology "Prof. Dr. Octavian Fodor" from ClujNapoca diagnosed with rectal cancer between 01.01.201131.12.2013. Were excluded from the analysis patients who were preoperatively staged by other imaging method such as MRI or CT and those who had performed ERUS in another medical service. It remained as an inclusion criteria the ERUS performed in IRGH "Prof. Dr. Octavian Fodor" Cluj-Napoca. We analyzed the preoperative stage, while the T stage obtained by ERUS was compared with the histopathological result from the excised pieces.

We examined the influence of gender on endorectal ultrasound staging. In case of pathological staging it was added as a factor of influence whether the patient performed neoadjuvant chemo-radiotherapy.

We also evaluated the influence of the patient gender and neoadjuvant therapy correlated with $\mathrm{T}$ stage on the number of affected lymph nodes.

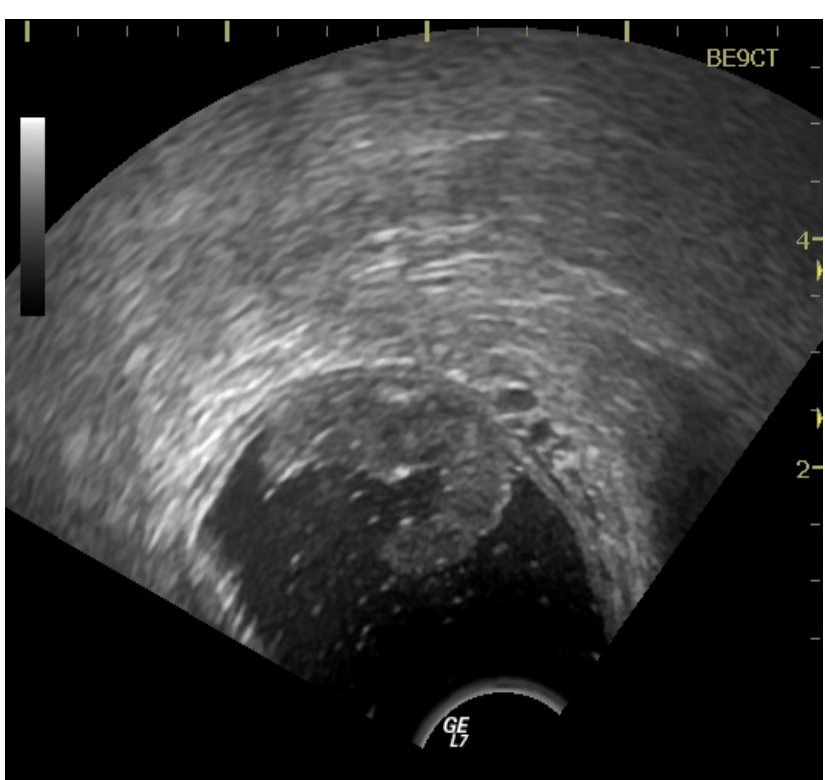

Figure 2. ERUS performed for a T1 rectal cancer.

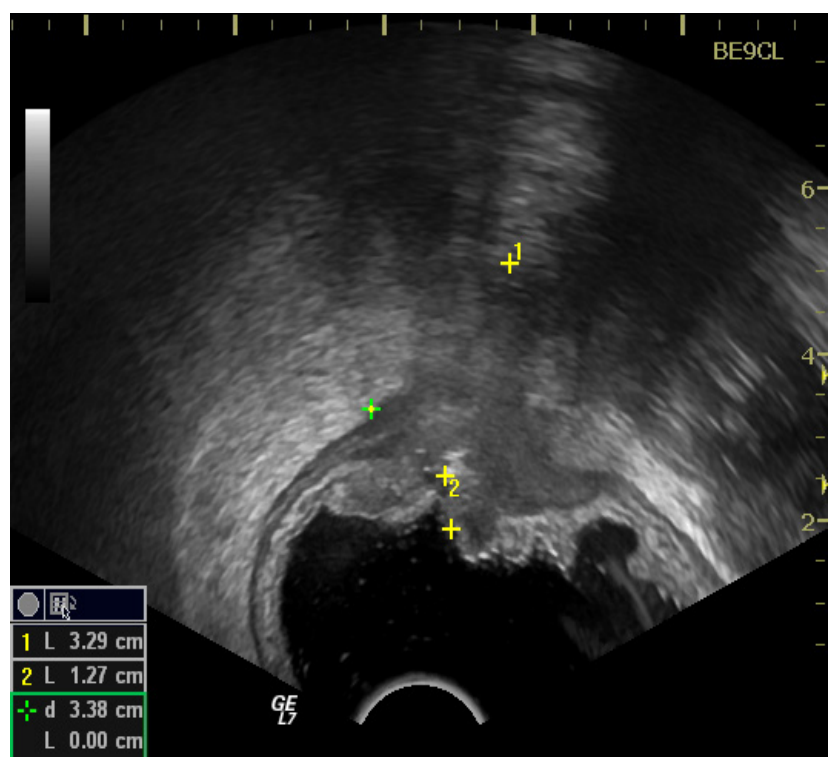

Figure 3. ERUS performed for a T3 rectal cancer.

As data consisted in nominal and ordinal variables, relationships among them were assessed with the help of the Chi-square test and the Kendall's correlation coefficient in the tau-b form and the Spearman's correlation coefficient. Crosstabulations were applied to see the sample's distribution on groups. Additionally, the clustered bar chart was constructed. Significance was considered at p-value $<0.05$ (Sig.). However, based on the actual probability given by the analysis, the critical level was either dropped at $1 \%$, or raised at $10 \%$. The actual confidence level use is specified for each individual analysis.

Statistical processing was performed using SPSS 20. uT represents the $\mathrm{T}$ staging obtained by endorectal ultrasonography (ERUS) and pT represents the T staging 
obtained after histopathological examination of the rectal tumor.

Before the ERUS examination, all patients were prepared with enemas to remove all stool, mucus and air from the rectum, which, if present, can create artifacts during the examination. The patients were positioned in the left lateral decubitus, and a digital rectal examination was performed. Following digital rectal examination, and after estimating tumor size and distance from the anal verge, the ERUS probe was prepared. A condom was placed over the crystal of the ERUS and the probe inserted into the rectum. Imaging of the rectum is initiated as the probe is withdrawn. The tumors were evaluated for size and depth of invasion, and the perirectal fat examined for suspicious lymph nodes. Other technique used in some cases was that after applying the condom, it was tied on the transducer with a rubber band. Once the probe inserted into the rectum, the condom can be inflated with water. Care must be taken to remove all air bubbles that might interfere with imaging. The amount of water used is established by the diameter of the rectal lumen, the level of patient discomfort, and the ability to traverse the lesion. This permits adequate conduction of sound waves through a strictly fluid medium, while minimizing compression and potential distortion of both the lesion and the surrounding anatomy.

\section{Results}

From the Surgical Clinic of the Regional Institute of Gastroenterology and Hepatology "Prof. Dr. Octavian
Fodor" (IRHG) of Cluj-Napoca were discharged with a diagnosis of rectal cancer in 2011 a total of 200 patients, of which 157 operated, in 2012 a total of 193 patients of which 151 operated, and in 2013 were discharged 198 patients of which operated 142 . We analyzed a total of 51 cases diagnosed with rectal cancer who performed ERUS in the imaging department of the IRGH Cluj-Napoca.

As a result of performing endorectal ultrasonography, 8 patients were preoperatively diagnosed with rectal cancer stage uT2, 38 patients with uT3 and 5 patients with stage uT4.

From Chart 1 it can be seen that the vast majority of patients were diagnosed by ERUS in stage uT3 $(74.5 \%)$, compared with 8 patients $(15.7 \%)$ in stage uT2 and 5 patients $(9.8 \%)$ in stage uT4.

After analyzing the pathological parts, rectal cancer staging accuracy by ERUS was confirmed in 23 patients with stage T3 out of 38 , which is $60.5 \%$ of the patients diagnosed as stage $\mathrm{T} 3$. This total of 23 patients represent $45.1 \%$ of those 51 patients investigated.

From Chart 1 it can also be seen that 5 patients were diagnosed by ERUS as stage uT4 and that after a thorough examination of the pathological result it was revealed that 3 patients $(5.88 \%)$ were in stage T3 and that only $2(3.92 \%)$ of 5 were indeed in stage T4. Stage T2 obtained by ERUS in 8 patients was confirmed in $50 \%$ of them, i.e. $7.8 \%$ of the total of 51 patients.

Analyzing the results in Table II it can be observed that out of the 8 patients (100\%) staged by ERUS as uT2

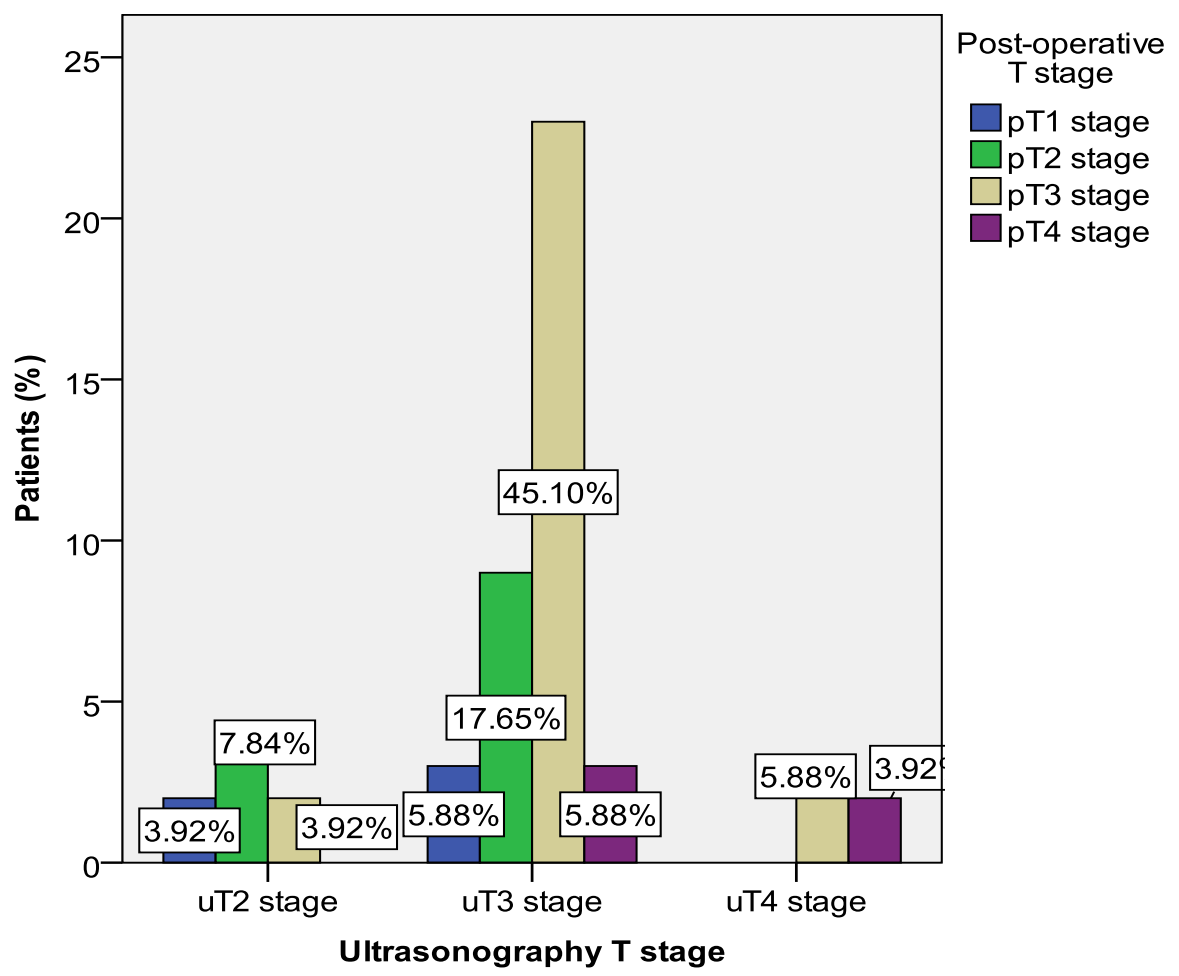

Chart 1. Graphic representation of T staging by ERUS correlated with the histopathological result. 
stage, $25 \%$ were over-staged and other $25 \%$ were understaged. There were 38 patients (100\%) diagnosed by ERUS in stage uT3 and from Tabel 2 it can be seen that $7.9 \%$ were under-staged (the histopathological examination staged them as pT4) and $31.6 \%$ (7.9\% in stage pT1 and $23.7 \%$ in stage pT2) were over-staged. ERUS staged 5 patients in stage uT4 and as it can be seen 3 of them $(60 \%)$ were in stage pT3. By ERUS we obtained a $60 \%$ over-stage for the patients with locally advanced tumors. All tumors in stage uT4 were stenosis tumors.

Assessing the relationship between the two types of staging, we find a statistically significant relationship at a confidence level of $99 \%$ ( $\mathrm{Sig}=0.001<0.01)$. Additionally, results show that between uT and pT there is a direct relationship of medium intensity (Kendall's coef. $=0.421$ $\epsilon(0.3 ; 0.7])$. The statistical significance is represented in the following Table III.

Given that some of the patients underwent preoperative neoadjuvant therapy such as chemotherapy
41 who did not receive neoadjuvant therapy, and of these only 1 patient was confirmed by pathology as T4 stage, the other being framed in stage T3. Both patients with stage T4 were presented to the emergency room of the Institute with clinical and imaging signs of intestinal occlusion. This is the reason of surgical interventions in these patients with T4 stage rectal cancer.

Neoadjuvant chemotherapy and radiotherapy was applied to a total of 10 patients from 51 analyzed. They were staged as T3 and T4. Of the 7 patients (70\%) who were before neoadjuvant chemo-radiotherapy in stage uT3, 3 patients $(30 \%)$ remained in the same stage, one $(10 \%)$ was staged with pT2 rectal cancer, and 3 patients $(30 \%)$ responded well at the neoadjuvant therapy and the pathological reultatul of the excised parts showed a pT1 stage.

Three patients (30\%) of 10 who underwent chemoradiotherapy before surgery were diagnosed with rectal cancer stage T4. After the neoadjuvant therapy and surgery

Tabel II. Over-staging and Under-staging of rectal cancer by ERUS.

\begin{tabular}{|c|c|c|c|c|c|c|c|}
\hline \multicolumn{8}{|c|}{ Over-staging and Under-staging of rectal cancer by ERUS } \\
\hline \multirow{5}{*}{$\begin{array}{l}\text { Ultra } \\
\text { sono } \\
\text { graphy } \\
\text { T stage }\end{array}$} & \multirow[b]{3}{*}{ uT2 } & \multirow[b]{3}{*}{$\begin{array}{l}\text { Number } \\
(\%)\end{array}$} & \multicolumn{4}{|c|}{ Post-operative T stage } & \multirow{2}{*}{ Total } \\
\hline & & & pT1 & pT2 & pT3 & pT4 & \\
\hline & & & $225.0 \%$ & $450.0 \%$ & $225.0 \%$ & 0 & $\begin{array}{l}8 \\
100 \%\end{array}$ \\
\hline & uT3 & $\begin{array}{l}\text { Number } \\
(\%)\end{array}$ & $37.9 \%$ & $923.7 \%$ & $2360.5 \%$ & $37.9 \%$ & $\begin{array}{l}38 \\
100 \%\end{array}$ \\
\hline & uT4 & Number $(\%)$ & 0 & 0 & $\begin{array}{l}3 \\
60 \%\end{array}$ & $\begin{array}{l}2 \\
40 \%\end{array}$ & $\begin{array}{l}5 \\
100 \%\end{array}$ \\
\hline Total & & N (\%) & $59.8 \%$ & $1325.5 \%$ & $2854.9 \%$ & $59.8 \%$ & $\begin{array}{l}51 \\
100 \%\end{array}$ \\
\hline
\end{tabular}

Tabel III. Correlation analysis between the ultrasonography T stage and the post-operative T stage (uT vs. pT).

\begin{tabular}{|c|c|c|c|c|c|}
\hline & & Value & $\begin{array}{l}\text { Asymp. } \\
\text { Std. Error }\end{array}$ & $\begin{array}{l}\text { Approx. } \\
\mathrm{T}\end{array}$ & $\begin{array}{l}\text { Approx. } \\
\text { Sig. }\end{array}$ \\
\hline \multirow{2}{*}{$\begin{array}{l}\text { Ordinal } \\
\text { by } \\
\text { Ordinal }\end{array}$} & $\begin{array}{l}\text { Kendall's } \\
\text { tau-b }\end{array}$ & .421 & .099 & 3.372 & .001 \\
\hline & $\begin{array}{l}\text { Spearman } \\
\text { Correlation }\end{array}$ & .454 & .105 & 3.564 & .001 \\
\hline \multicolumn{2}{|c|}{$\begin{array}{l}\text { Number of Valid } \\
\text { Cases }\end{array}$} & 51 & & & \\
\hline
\end{tabular}

and radiotherapy the relationship between staging obtained by endorectal ultrasonography (ERUS) and the result from the anatomo-pathology was evaluated, depending on the application or not of neoadjuvant treatment.

Of a total of 41 patients $(100 \%)$ who did not receive neoadjuvant treatment, 4 patients $(9.8 \%)$ were diagnosed and confirmed by morpho-pathology as stage T2, 20 patients $(48.8 \%)$ were diagnosed as stage T3 and were confirmed in this stage by morphopathology. By ERUS we diagnosed only 2 patients $(4.9 \%)$ with rectal cancer in stage $\mathrm{T} 4$ of the one patient $(10 \%)$ remained in $\mathrm{T} 4$, which did not respond to chemo-radiotherapy and required emergency surgery because occlusion was onset, and 2 patients $(20 \%)$ passed in $\mathrm{pT} 3$, which allowed the tumor surgical excision with R0 margins.

Statistical significance of the results is shown in the following Table V.

Group analysis shows that for patients who did not undergo preoperative therapy the relationship remains significant at the $1 \%$ critical level $(\mathrm{Sig}=0.002<0.01)$. Evaluation of correlation coefficients for the two groups returns the same result (direct, medium intensity relationship) but with higher values of coefficients for patients who did neoadjuvant therapy ( 0.476 vs. 0.579$)$.

Influences of gender and staging on the number of tumor affected lymph nodes were also evaluated. This analysis was performed depending on the presence or absence of neoadjuvant chemotherapy and radiotherapy.

The results are shown in the following Tables VI and VII. 
Tabel IV. uT and pT staging in relation to neoadjuvant therapy.

\begin{tabular}{|c|c|c|c|c|c|c|c|c|}
\hline \multicolumn{9}{|c|}{$\mathrm{uT}$ and $\mathrm{pT}$ staging according to neoadjuvant therapy } \\
\hline \multirow{2}{*}{\multicolumn{4}{|c|}{$\begin{array}{l}\text { Radio-chemotherapy before } \\
\text { surgery }\end{array}$}} & \multicolumn{4}{|c|}{ Post-operative T stage } & \multirow{3}{*}{$\begin{array}{c}\text { Total } \\
8 \\
19.5 \% \\
\end{array}$} \\
\hline & & & & \multirow{2}{*}{$\begin{array}{c}\mathrm{pT} 1 \\
2 \\
4.9 \%\end{array}$} & \multirow{2}{*}{$\begin{array}{c}\text { pT2 } \\
4 \\
9.8 \%\end{array}$} & \multirow{2}{*}{$\begin{array}{c}\mathrm{pT} 3 \\
2 \\
4.9 \%\end{array}$} & \multirow{2}{*}{$\frac{\mathrm{pT} 4}{0}$} & \\
\hline \multirow{4}{*}{ No } & \multirow{3}{*}{$\begin{array}{l}\text { Ultra } \\
\text { sono } \\
\text { graphy } \\
\mathrm{T} \\
\text { stage }\end{array}$} & uT2 & $\begin{array}{l}\mathrm{Nr} . \\
(\%)\end{array}$ & & & & & \\
\hline & & uT3 & $\begin{array}{l}\mathrm{Nr} . \\
(\%)\end{array}$ & 0 & $\begin{array}{c}8 \\
19.5 \% \\
\end{array}$ & $\begin{array}{c}20 \\
48.8 \% \\
\end{array}$ & $\begin{array}{l}3 \\
7.3 \% \\
\end{array}$ & $\begin{array}{c}31 \\
75.6 \% \\
\end{array}$ \\
\hline & & uT4 & $\begin{array}{l}\mathrm{Nr} . \\
(\%)\end{array}$ & 0 & 0 & $\begin{array}{c}1 \\
2.4 \% \\
\end{array}$ & $\begin{array}{c}1 \\
2.4 \% \\
\end{array}$ & $\begin{array}{c}2 \\
4.8 \% \\
\end{array}$ \\
\hline & Total & & $\begin{array}{l}\mathrm{Nr} . \\
(\%)\end{array}$ & $\begin{array}{c}2 \\
4.9 \% \\
\end{array}$ & $\begin{array}{c}12 \\
29.3 \% \\
\end{array}$ & $\begin{array}{c}23 \\
56.1 \% \\
\end{array}$ & $\begin{array}{c}4 \\
9.8 \% \\
\end{array}$ & $\begin{array}{c}41 \\
100 \% \\
\end{array}$ \\
\hline \multirow{3}{*}{ Yes } & \multirow{2}{*}{$\begin{array}{l}\text { Ultra } \\
\text { sono } \\
\text { graphy } \\
\mathrm{T} \\
\text { stage }\end{array}$} & uT3 & $\begin{array}{l}\mathrm{Nr} . \\
(\%)\end{array}$ & $\begin{array}{c}3 \\
30 \% \\
\end{array}$ & $\begin{array}{c}1 \\
10 \% \\
\end{array}$ & $\begin{array}{c}3 \\
30 \% \\
\end{array}$ & 0 & $\begin{array}{c}7 \\
70 \% \\
\end{array}$ \\
\hline & & uT4 & $\begin{array}{l}\mathrm{Nr} \\
(\%)\end{array}$ & 0 & 0 & $\begin{array}{c}2 \\
20 \%\end{array}$ & $\begin{array}{c}1 \\
10 \%\end{array}$ & $\begin{array}{c}3 \\
30 \%\end{array}$ \\
\hline & Total & & $\begin{array}{l}\mathrm{Nr} . \\
(\%)\end{array}$ & $\begin{array}{c}3 \\
30 \% \\
\end{array}$ & $\begin{array}{c}1 \\
10 \% \\
\end{array}$ & $\begin{array}{c}5 \\
50 \% \\
\end{array}$ & $\begin{array}{c}1 \\
10 \% \\
\end{array}$ & $\begin{array}{c}10 \\
100 \% \\
\end{array}$ \\
\hline \multirow{4}{*}{ Total } & \multirow{3}{*}{$\begin{array}{l}\text { Ultra } \\
\text { sono } \\
\text { graphy } \\
\mathrm{T} \\
\text { stage }\end{array}$} & uT2 & $\begin{array}{l}\mathrm{Nr} . \\
(\%)\end{array}$ & $\begin{array}{c}2 \\
3.9 \% \\
\end{array}$ & $\begin{array}{c}4 \\
7.8 \% \\
\end{array}$ & $\begin{array}{c}2 \\
3.9 \% \\
\end{array}$ & 0 & $\begin{array}{c}8 \\
15.7 \% \\
\end{array}$ \\
\hline & & uT3 & $\begin{array}{l}\text { Nr. } \\
(\%)\end{array}$ & $\begin{array}{c}3 \\
5.9 \% \\
\end{array}$ & $\begin{array}{c}9 \\
17.6 \% \\
\end{array}$ & $\begin{array}{c}23 \\
45.1 \% \\
\end{array}$ & $\begin{array}{c}3 \\
5.9 \% \\
\end{array}$ & $\begin{array}{c}38 \\
74.5 \% \\
\end{array}$ \\
\hline & & uT4 & $\begin{array}{l}\mathrm{Nr} . \\
(\%)\end{array}$ & 0 & 0 & $\begin{array}{c}3 \\
5.9 \% \\
\end{array}$ & $\begin{array}{c}2 \\
3.9 \% \\
\end{array}$ & $\begin{array}{c}5 \\
9.8 \% \\
\end{array}$ \\
\hline & Total & & $\begin{array}{l}\text { Nr. } \\
(\%) \\
\end{array}$ & $\begin{array}{c}5 \\
9.8 \% \\
\end{array}$ & $\begin{array}{c}13 \\
25.5 \% \\
\end{array}$ & $\begin{array}{c}28 \\
54.9 \% \\
\end{array}$ & $\begin{array}{c}5 \\
9.8 \% \\
\end{array}$ & $\begin{array}{c}51 \\
100 \% \\
\end{array}$ \\
\hline
\end{tabular}

Tabel V. Correlation between uT and pT based on Radio-chemotherapy before surgery.

\begin{tabular}{|c|c|c|c|c|c|c|}
\hline \multicolumn{3}{|c|}{ Radio-chemotherapy before surgery } & Value & $\begin{array}{l}\text { Asymp. } \\
\text { Std. Error }\end{array}$ & $\begin{array}{l}\text { Approx. } \\
\mathrm{T}\end{array}$ & $\begin{array}{l}\text { Approx } \\
\text { Sig. }\end{array}$ \\
\hline \multirow{3}{*}{ No } & \multirow{2}{*}{$\begin{array}{l}\text { Ordinal } \\
\text { by Ordinal }\end{array}$} & Kendall's tau-b & .476 & .116 & 3.129 & .002 \\
\hline & & Spearman Correlation & .502 & .123 & 3.628 & .001 \\
\hline & \multicolumn{2}{|c|}{ Number of Valid Cases } & 41 & & & \\
\hline \multirow{3}{*}{ Yes } & \multirow{2}{*}{$\begin{array}{l}\text { Ordinal } \\
\text { by Ordinal }\end{array}$} & Kendall's tau-b & .579 & .127 & 2.739 & .006 \\
\hline & & Spearman Correlation & .616 & .145 & 2.214 & .058 \\
\hline & \multicolumn{2}{|c|}{ Number of Valid Cases } & 10 & & & \\
\hline \multirow{3}{*}{ Total } & \multirow{2}{*}{$\begin{array}{l}\text { Ordinal } \\
\text { by Ordinal }\end{array}$} & Kendall's tau-b & .421 & .099 & 3.372 & .001 \\
\hline & & Spearman Correlation & .454 & .105 & 3.564 & .001 \\
\hline & \multicolumn{2}{|c|}{ Number of Valid Cases } & 51 & & & \\
\hline
\end{tabular}


Tabel VI. Nodal status according to the T staging by morphopathology correlated with patient gender and neoadjuvant radio-chemotherapy (gender: male).

\begin{tabular}{|c|c|c|c|c|c|c|c|c|}
\hline \multicolumn{9}{|c|}{$\begin{array}{l}\text { Nodal status according to the } \mathrm{T} \text { staging by pathology correlated with patient sex and } \\
\text { neoadjuvant radio-chemotherapy (gender: male) }\end{array}$} \\
\hline \multirow{2}{*}{ Sex } & \multirow{2}{*}{\multicolumn{4}{|c|}{$\begin{array}{l}\text { Radio-chemotherapy before } \\
\text { surgery }\end{array}$}} & \multicolumn{3}{|c|}{ Nodal status } & \multirow{2}{*}{ Total } \\
\hline & & & & & No & N 1 & N 2 & \\
\hline \multirow{10}{*}{ Male } & \multirow{5}{*}{ No } & \multirow{4}{*}{$\mathrm{pT}$} & pT1 & $\begin{array}{l}\text { N. } \\
(\%)\end{array}$ & $\begin{array}{l}2 \\
6.7 \% \\
\end{array}$ & 0 & 0 & $\begin{array}{l}2 \\
6.7 \% \\
\end{array}$ \\
\hline & & & pT2 & $\begin{array}{l}\mathrm{Nr} . \\
(\%)\end{array}$ & $\begin{array}{l}5 \\
16.7 \% \\
\end{array}$ & $\begin{array}{l}3 \\
10 \% \\
\end{array}$ & 0 & $\begin{array}{l}8 \\
26.7 \%\end{array}$ \\
\hline & & & pT3 & $\begin{array}{l}\mathrm{Nr} . \\
(\%)\end{array}$ & $\begin{array}{l}82 \\
6.7 \% \\
\end{array}$ & $\begin{array}{l}6 \\
20 \% \\
\end{array}$ & $\begin{array}{l}3 \\
10 \% \\
\end{array}$ & $\begin{array}{l}17 \\
56.7 \%\end{array}$ \\
\hline & & & pT4 & $\begin{array}{l}\mathrm{Nr} . \\
(\%)\end{array}$ & 0 & $\begin{array}{l}2 \\
6.7 \% \\
\end{array}$ & $\begin{array}{l}1 \\
3.3 \% \\
\end{array}$ & $\begin{array}{l}3 \\
10 \% \\
\end{array}$ \\
\hline & & Total & & $\begin{array}{l}\text { Nr. } \\
(\%)\end{array}$ & $\begin{array}{l}15 \\
50 \% \\
\end{array}$ & $\begin{array}{l}11 \\
36.7 \% \\
\end{array}$ & $\begin{array}{l}4 \\
13.3 \% \\
\end{array}$ & $\begin{array}{l}30 \\
100 \% \\
\end{array}$ \\
\hline & \multirow{5}{*}{ Yes } & \multirow{4}{*}{$\mathrm{pT}$} & pT1 & $\begin{array}{l}\mathrm{Nr} . \\
(\%)\end{array}$ & 0 & $\begin{array}{l}1 \\
12.5 \% \\
\end{array}$ & & $\begin{array}{l}1 \\
12.5 \%\end{array}$ \\
\hline & & & pT2 & $\begin{array}{l}\text { Nr. } \\
(\%)\end{array}$ & $\begin{array}{l}1 \\
12.5 \% \\
\end{array}$ & 0 & & $\begin{array}{l}1 \\
12.5 \% \\
\end{array}$ \\
\hline & & & pT3 & $\begin{array}{l}\mathrm{Nr} . \\
(\%)\end{array}$ & $\begin{array}{l}4 \\
50 \% \\
\end{array}$ & $\begin{array}{l}1 \\
2.5 \% \\
\end{array}$ & & $\begin{array}{l}5 \\
62.5 \% \\
\end{array}$ \\
\hline & & & pT4 & $\begin{array}{l}\text { Nr. } \\
(\%)\end{array}$ & $\begin{array}{l}1 \\
12.5 \% \\
\end{array}$ & 0 & & $\begin{array}{l}1 \\
12.5 \%\end{array}$ \\
\hline & & Total & & $\begin{array}{l}\text { Nr. } \\
(\%)\end{array}$ & $\begin{array}{l}6 \\
75 \% \\
\end{array}$ & $\begin{array}{l}2 \\
25 \% \\
\end{array}$ & & $\begin{array}{l}8 \\
100 \% \\
\end{array}$ \\
\hline
\end{tabular}

Tabel VII. Nodal status according to the T staging by pathology correlated with patient gender and neoadjuvant radio-chemotherapy (gender: female).

\begin{tabular}{|c|c|c|c|c|c|c|c|c|}
\hline \multicolumn{9}{|c|}{$\begin{array}{l}\text { Nodal status according to the } T \text { staging by pathology correlated with gender and } \\
\text { neoadjuvant radio-chemotherapy (gender: female) }\end{array}$} \\
\hline \multirow{2}{*}{ Sex } & \multirow{2}{*}{\multicolumn{4}{|c|}{$\begin{array}{l}\text { Radio-chemotherapy before } \\
\text { surgery }\end{array}$}} & \multicolumn{3}{|c|}{ Nodal status } & \multirow{2}{*}{ Total } \\
\hline & & & & & N 0 & N 1 & N 2 & \\
\hline \multirow{6}{*}{ Female } & \multirow{4}{*}{ No } & \multirow{3}{*}{$\mathrm{pT}$} & pT2 & $\begin{array}{l}\text { Nr. } \\
(\%)\end{array}$ & $\begin{array}{l}4 \\
25 \% \\
\end{array}$ & 0 & 0 & $\begin{array}{l}4 \\
25 \% \\
\end{array}$ \\
\hline & & & pT3 & $\begin{array}{l}\text { Nr. } \\
(\%)\end{array}$ & $\begin{array}{l}3 \\
18.8 \%\end{array}$ & $\begin{array}{l}4 \\
25 \%\end{array}$ & $\begin{array}{l}4 \\
25 \%\end{array}$ & $\begin{array}{l}11 \\
8.8 \%\end{array}$ \\
\hline & & & pT4 & $\begin{array}{l}\text { Nr. } \\
(\%)\end{array}$ & 0 & $16.3 \%$ & 0 & $\begin{array}{l}1 \\
6.3 \%\end{array}$ \\
\hline & & Total & & $\begin{array}{l}\text { Nr. } \\
(\%)\end{array}$ & $\begin{array}{l}7 \\
43.8 \%\end{array}$ & $\begin{array}{l}5 \\
31.3 \%\end{array}$ & $\begin{array}{l}4 \\
25 \%\end{array}$ & $\begin{array}{l}16 \\
100 \%\end{array}$ \\
\hline & \multirow{2}{*}{ Yes } & $\mathrm{pT}$ & pT1 & $\begin{array}{l}\text { Nr. } \\
(\%)\end{array}$ & $\begin{array}{l}1 \\
100 \% \\
\end{array}$ & & & $\begin{array}{l}1 \\
100 \%\end{array}$ \\
\hline & & Tota & & N (\%) & $\begin{array}{l}1 \\
100 \%\end{array}$ & & & $\begin{array}{l}1 \\
100 \%\end{array}$ \\
\hline
\end{tabular}

\section{Discussion}

Rectal cancer surgery, subject in recent years of some important clarifications regarding therapeutic and surgical tactics, still continues to raise discussions on early diagnosis, staging and uniform application of therapeutic protocols, with particular reference to preoperative chemoradiotherapy. It is known that improving prognosis in any malignant neoplasia is strictly an early detection system in curable stages.

Therefore endorectal ultrasonography (ERUS) is likely to remain one of the most used methods for diagnosing and staging rectal cancer.

The European Registration of Cancer Care (EURECCA) has stated that ERUS is the most accurate method for evaluating tumor penetration into the rectal wall. However, ERUS is quite operator-dependent and experience affects the results [14].

The results of this study are within the limits offered by other studies, and as a result we can say that endorectal ultrasound performed in IRGH Cluj-Napoca is a reliable 
method for staging rectal cancer.

According to some studies ERUS is considered to be more accurate than computed tomography (CT) or magnetic resonance (MRI) in evaluating the depth of tumor invasion, especially in the early stages of $\mathrm{T} 1$ and $\mathrm{T} 2$ tumors, because of its ability to clearly identify the layers of the rectal wall as it can be seen in Figure 1, 2 and 3 [15-18].

MRI has been shown to be the most accurate imaging modality for local rectal cancer staging, particularly in advanced T3 and T4 tumors [19,20].

Compared to MRI, ERUS has the advantages of being less costly and available in many ultrasound offices, offering real-time imaging [21].

Since the addition of ERUS to routine workup for rectal cancer, the number of patients receiving neoadjuvant therapy has risen. Given the risk of overstaging, it is possible that some patients are being overtreated [22].

Preoperative staging of rectal cancer is very important to be done as accurately as possible because an advanced diagnosis such as T3-4 or N1-2 leads to applying chemo-radiotherapy which can be accompanied by side effects. Wound infection and perineal wound dehiscence, radiation cystitis, enteritis, proctitis and anastomotic dehiscence are more common in irradiated patients [23].

Several studies compared the efficiency of preoperative or post-operative chemo-radiotherapy (CRT) in patients with clinical stage $\mathrm{T} 3$ or $\mathrm{T} 4$ or node-positive disease. The conclusion is that pre-operative CRT is more efficient, less-toxic and more dose-efficient than the postoperative method [24-26].

The circumferential resection margin (CRM) is highly prognostic for local recurrence in rectal cancer surgery without neoadjuvant treatment.

The optimal cutoff for defining positive CRM is still debated, however, and some investigators propose $2 \mathrm{~mm}$ rather than $1 \mathrm{~mm}$.

The 5-year local recurrence-free survival is significantly different in patients with $\mathrm{CRM} \leq 1 \mathrm{~mm}$ than in patients with CRM $>1 \mathrm{~mm}$ (66 vs $98 \%$ ) [27].

Therefore for rectal cancer stage $\mathrm{T} 3$ or T4 neoadjuvant treatment is required, just to avoid getting circumferential resection margins $<1 \mathrm{~mm}$ and thus to avoid recurrences. But if the patient is over-staged by ERUS, do we submit them to neoadjuvant treatment?

Examination with a contrast agent is a way to optimize endorectal ultrasound by realizing a "removal" of the region of interest from the transducer, facilitating the focalization of ultrasound. The shape of transducer is important in order to obtain a quality image. For tumor staging a mechanical transducer is ideal because the uniform rotation provides $360^{\circ}$ allowing the view of whole rectal circumference and the ultrasound beam has a perpendicular angle on the mucosa surface [28].

All we have to do is to make rectal cancer staging as accurate as possible. This way a treatment protocol can be applied according to each stage and thus chemoradiotherapy treatment is avoided in patients who do not need it.

\section{Conclusions}

Endorectal Ultrasonography (ERUS) is one of the most used imaging method for staging rectal cancer. The accuracy of this imaging method is dependent on multiple factors including operator expertise, peritumoral inflammation and edema, and is complicated by the potential for over-staging and under-staging. Endorectal ultrasound is a safe, inexpensive and accurate staging method for the assessment of both depth of infiltration and nodal status.

ERUS is less accurate for $\mathrm{T}$ staging of stenotic tumors, for example those in stage uT4, but the accuracy may still be within acceptable limits.

Surgeons use ERUS to adopt a treatment protocol, knowing the risk of under-staging and over-staging of this method. The accuracy of ERUS is higher in diagnosing rectal cancer in stages $\mathrm{T} 1, \mathrm{~T} 2$ and even in stage $\mathrm{T} 3$ with malignant tumor which is not occlusive.

Preoperative staging of rectal cancer by ERUS is a useful modality in determining the need for preoperative chemotherapy and radiotherapy. The ERUS $\mathrm{T}$ staging following chemo-radiotherapy appears to be less accurate due to peritumoral inflammation and fibrosis.

Clinical examination of the patient must focus on the possibility of performing ERUS and help us decide which imaging method to use for staging rectal cancer. ERUS can be performed at the time of patient evaluation with minimal preparation or patient discomfort.

It is a necessity to identify the number of malignant lymph nodes by endorectal ultrasonography (ERUS) with or without contrast and their topography.

Oncologic neoadjuvant treatment in stages T3 and T4 must be administered. (It reduces the tumor size and sterilizes lymph nodes as shown in this study).

\section{Acknowledgement}

This paper was published under the frame of European Social Fund, Human Resources Development Operational Program 2007-2013, project no. POSDRU /159/1.5/S/138776.

\section{References}

1. Doci R, Bignami P, Montalto F, Gennari L. Prognostic factors for survival and disease-free survival in hepatic metastases from colorectal cancer treated by resection. Tumori. 1995;81(3 Suppl):143-146.

2. Fong Y, Blumgart LH. Hepatic colorectal metastasis: current status of surgical therapy. Oncology (Williston Park). 1998;12(10):1489-1498.

3. Miron L, Marinca M. Tratamentul sistemic al cancerului colorectal metastatic: standarde actuale, optiuni viitoare [Systemic 
therapy of metastatic colorectal cancer: current standards, future options]. Jurnalul de Chirurgie, Iasi. 2006;2 (3):260-267.

4. Wagner JS, Adson MA, Van Heerden JA, Adson MH, Ilstrup DM. The natural history of hepatic metastases from colorectal cancer. A comparison with resective treatment. Ann Surg. 1984;199(5):502-508.

5. Glimelius B, Pahlman L, Cervantes A, ESMO Guidelines Working Group. Rectal cancer: ESMO Clinical Practice Guidelines for diagnosis, treatment and follow-up. Ann Oncol. 2010;21 Suppl 5:v82-v86.

6. Heo SH, Kim JW, Shin SS, Jeong YY, Kang HK. Multimodal imaging evaluation in staging of rectal cancer. World $\mathrm{J}$ Gastroenterol. 2014;20(15):4244-4255.

7. Kuran S, Ozin Y, Nessar G, Turhan N, Sasmaz N. Is endorectal ultrasound still useful for staging rectal cancer?. Eur Rev Med Pharmacol Sci. 2014;18(19):2857-2862.

8. Krajewski KM Kane RA. Ultrasound staging of rectal cancer. Semin Ultrasound CT MR. 2008;29(6):427-432.

9. Cartana ET, Parvu D, Saftoiu A. Endoscopic ultrasound: current role and future perspectives in managing rectal cancer patients. $\mathrm{J}$ Gastrointestin Liver Dis. 2011;20(4):407-413.

10. Samee A, Selvasekar CR. Current trends in staging rectal cancer. World J Gastroenterol. 2011;17(7):828-834.

11. De Nardi P, Carvello M. How reliable is current imaging in restaging rectal cancer after neoadjuvant therapy? World J Gastroenterol. 2013;19(36):5964-5972.

12. Kav T, Bayraktar Y. How useful is rectal endosonography in the staging of rectal cancer?. World J Gastroenterol. 2010;16(6):691697.

13. Rafaelsen SR, Vagn-Hansen C, Sørensen T, Pløen J, Jakobsen A. Transrectal ultrasound and magnetic resonance imaging measurement of extramural tumor spread in rectal cancer. World J Gastroenterol. 2012;18(36):5021-5026.

14. van de Velde CJ, Boelens PG, Borras JM, Coebergh JW, Cervantes A, Blomqvist L, et al. EURECCA colorectal: multidisciplinary management: European consensus conference colon \& rectum. Eur J Cancer. 2014;50(1):1.e1-1.e34.

15. Saranovic D, Barisic G, Krivokapic Z, Masulovic D, DjuricStefanovic A. Endoanal ultrasound evaluation of anorectal diseases and disorders: technique, indications, results and limitations. Eur J Radiol. 2007;61(3):480-489.

16. Saftoiu A, Gheonea DI. Tridimensional (3D) endoscopic ultrasound - a pictorial review. J Gastrointestin Liver Dis. 2009;18(4):501-505.
17. Samdani T, Garcia-Aguilar J. Imaging in rectal cancer: magnetic resonance imaging versus endorectal ultrasonography. Surg Oncol Clin N Am. 2014;23(1):59-77.

18. Rovera F, Dionigi G, Boni L, Cutaia S, Diurni M, Dionigi R. The role of EUS and MRI in rectal cancer staging. Surg Oncol. 2007;16 Suppl 1:51-52.

19. Bipat S, Glas AS, Slors FJ, Zwinderman AH, Bossuyt PM, Stoker J. Rectal cancer: local staging and assessment of lymph node involvement with endoluminal US, CT, and MR imaging--a meta-analysis. Radiology. 2004;232(3):773-783.

20. Kim MJ. Transrectal ultrasonography of anorectal diseases: advantages and disadvantages. Ultrasonography. 2015;34(1):1931.

21. Beets GL, Beets-Tan RG. Pretherapy imaging of rectal cancers: ERUS or MRI?. Surg Oncol Clin N Am. 2010;19(4):733741.

22. Edelman BR, Weiser MR. Endorectal ultrasound: its role in the diagnosis and treatment of rectal cancer. Clin Colon Rectal Surg. 2008;21(3):167-177.

23. Patrascu T, Doran H, Mihalache O. Preoperative radiotherapy in rectal cancer treatment -- is it really a gold standard?. Chirurgia (Bucur). 2014;109(2):185-190.

24. Sauer R, Becker H, Hohenberger W, Rodel C, Wittekind C, Fietkau R, et al. Preoperative versus postoperative chemoradiotherapy for rectal cancer. $N$ Engl $J$ Med. 2004;351:1731-1740.

25. Sauer R, Liersch T, Merkel S, Fietkau R, Hohenberger W, Hess $\mathrm{C}$, et al. Preoperative versus postoperative chemoradiotherapy for locally advanced rectal cancer: results of the German CAO/ARO/ AIO-94 randomized phase III trial after a median follow-up of 11 years. J Clin Oncol 2012;30:1926-1933.

26. Seery TE, Ziogas A, Lin BS, Pan CJ, Stamos MJ, Zell JA. Mortality risk after preoperative versus postoperative chemotherapy and radiotherapy in lymph node-positive rectal cancer. J Gastrointest Surg. 2013;17(2):374-381.

27. Trakarnsanga A, Gonen M, Shia J, Goodman KA, Nash GM, Temple LK, et al. What is the significance of the circumferential margin in locally advanced rectal cancer after neoadjuvant chemoradiotherapy?. Ann Surg Oncol. 2013;20(4):1179-1184.

28. Badea R, Ciobanu L, Gomotirceanu A, Hagiu C, Socaciu M. Contrast ultrasonography of the digestive tract lumen. Review of the literature and personal experience. Med Ultrason. 2010;12(1):52-61. 